\title{
The Uptake of Some Sulphur-containing Amino Acids by a Brewer's Yeast
}

\author{
By G. A. MAW \\ Arthur Guinness Son \& Co. (Dublin) Ltd, Dublin, Eire
}

(Received 13 September 1962)

\begin{abstract}
SUMMARY
A study of the accumulation by a brewer's yeast of six sulphur-containing amino acids labelled with sulphur-35 showed several distinct patterns of uptake. L-Methionine was accumulated rapidly and completely from the medium, L-cysteine was taken up slowly, and L-cystine not at all. DLEthionine accumulation was incomplete. $S$-Methyl-L-cysteine and $S$-ethyl-L-cysteine were taken up rapidly for a short period, and part of the sulphur of these compounds was then released into the medium. Accumulation of the sulphur amino acids was inhibited by certain other amino acids with a close structural relationship to them and when present in high concentration. Cysteine uptake was enhanced by the presence of reduced glutathione. These effects on accumulation were shown to be primarily changes in the transport of the sulphur amino acids into the yeast, although subsequent incorporation into protein may also be affected.
\end{abstract}

\section{INTRODUCTION}

Previous studies (Maw, 1960, 1961 $a, b$ ) on the ability of various compounds to act as sources of sulphur for the growth of a strain of Saccharomyces cerevisiae indicated marked differences between the sulphur-containing amino acids. Whereas L-methionine was almost as effective a sulphur source as inorganic sulphate, $S$-methyl-L-cysteine was poorly so, and L-cysteine, $S$-ethyl-L-cysteine and Lethionine were inhibitory of growth. In view of these findings the mode of uptake of these compounds and the extent of utilization of their sulphur by the yeast was examined. The present paper deals with a comparison of the rates of uptake by yeast suspensions of sulphate and six sulphur-containing amino acids, the compounds used being labelled with sulphur-35. Striking differences in rate and pattern of uptake were found which have a bearing on some of the findings of the growth experiments reported earlier; for example, the differences in effectiveness between methionine, cysteine and $S$-methylcysteine when used as sulphur sources. An examination of the effects on the uptake of the labelled compounds of several related compounds was also made, to provide information on the specificity of the uptake mechanisms. In several instances changes in uptake of the sulphur amino acids were observed, although in general a high concentration of added compound was necessary to produce any marked effect. Trichloroacetic acid fractionation of materials containing the labelled sulphur which entered the yeast was then carried out to determine whether the changes which occurred were due entirely to effects on the amino acid transport mechanism, or whether other factors, such as intracellular incorporation, were involved. A preliminary account of some aspects of this work has already been reported (Maw, 1961c). 


\section{METHODS}

Media for growth and uptake experiments. For growth of the yeast a medium of the following composition was used (the amounts given are for 11 . final medium): glucose, 50 g.; $\mathrm{NH}_{4} \mathrm{Cl}, 1.52 \mathrm{~g}$.; $\mathrm{KCl}, 0.42 \mathrm{~g}$.; $\mathrm{KH}_{2} \mathrm{PO}_{4}, 0.55$ g.; potassium citrate monohydrate, $5 \mathrm{~g}$.; citric acid, $1.125 \mathrm{~g}$.; $\mathrm{CaCl}_{2} \cdot 6 \mathrm{H}_{2} \mathrm{O}, 0.2 \mathrm{~g}$.; $\mathrm{MgCl}_{2} \cdot 6 \mathrm{H}_{2} \mathrm{O}, 0 \cdot 1 \mathrm{~g}$.; $\mathrm{MnCl}_{2} \cdot 4 \mathrm{H}_{2} \mathrm{O}, 5 \mathrm{mg}$; $\mathrm{FeCl}_{3}, 4 \cdot 5 \mathrm{mg}$; $\mathrm{CuCl}_{2} \cdot 2 \mathrm{H}_{2} \mathrm{O}, 0 \cdot 36 \mathrm{mg}$; $\mathrm{Na}_{2} \mathrm{MoO}_{4} \cdot 2 \mathrm{H}_{2} \mathrm{O}$, 0.34 mg.; $\mathrm{H}_{3} \mathrm{BO}_{3}, 0 \cdot 6 \mathrm{mg}$.; $\left(\mathrm{CH}_{3} . \mathrm{CO}_{2}\right)_{2} \mathrm{Zn} .2 \mathrm{H}_{2} \mathrm{O}, 6 \cdot 8 \mathrm{mg}$.; inositol, $25 \mathrm{mg}$.; thiamine chloride, $0.5 \mathrm{mg}$.; pyridoxine, $0.5 \mathrm{mg}$; calcium pantothenate, $10 \mathrm{mg}$; biotin, $0 \cdot 1 \mathrm{mg}$. Sodium sulphate was added to give a final concentration of $0.312 \mathrm{~mm}$ (10 mg. sulphate-S/l.). This medium without the sulphate was used in the uptake experiments and is referred to as the sulphate-free medium.

Yeast used. A Guinness strain of Saccharomyces cerevisiae was used. The yeast was grown from a small inoculum in the sulphate-containing medium for 2 days at $30^{\circ}$ with shaking. The yeast was harvested by filtration, washed free from sulphate by three resuspensions in $\mathbf{0 . 8 5} \%$ sodium chloride solution and partly dried by suction on a Buchner funnel for $15 \mathrm{~min}$. The yield from $400 \mathrm{ml}$. medium was 7-8 g. wet weight pressed yeast. Suspensions $(20 \%$ wet weight pressed yeast/vol. were prepared in water. Yeast dry weight contents were obtained by centrifuging off the yeast and drying to constant weight at $104^{\circ}$.

Compounds used. Sodium [ $\left.{ }^{35} \mathrm{~S}\right]$ sulphate (carrier-free) and DL-[ $\left.{ }^{35} \mathrm{~S}\right]$ ethionine (1.14 mC./m-mole) were purchased from the Radiochemical Centre, Amersham, Buckinghamshire.

${ }_{\mathrm{L}-}\left[{ }^{35} \mathrm{~S}\right] \mathrm{Cystine}$ and $\mathrm{L}-\left[{ }^{35} \mathrm{~S}\right]$ methionine were obtained biosynthetically by growing the yeast in the sulphate medium described above, supplemented with carrier-free $\mathrm{Na}_{2}{ }^{35} \mathrm{SO}_{4}(2 \mathrm{mC}$./l. medium). The methods for the isolation of the labelled compounds followed closely those of Williams \& Dawson (1952). In their preparations these workers used a medium containing about $60 \mathrm{mg}$. sulphate-S/l. In the present work, more efficient incorporation of sulphur-35 by the yeast was ensured by keeping the sulphate content of the medium in the region of $10 \mathrm{mg} . \mathrm{S} / \mathrm{l}$. which is just adequate for optimum growth (Maw, 1960).

$S$-Methyl-L-[ ${ }^{35}$ S $]$ cysteine and $S$-ethyl-L- $\left[{ }^{35}\right.$ S $]$ cysteine were prepared from L$\left[{ }^{35} \mathrm{~S}\right]$ cystine by reduction with sodium in anhydrous ammonia followed by alkylation with the appropriate alkyl iodide (du Vigneaud, Loring \& Craft, 1934). The alkylcysteines were extracted with $95 \%(\mathrm{v} / \mathrm{v})$ ethanol in water and recrystallized once from this solvent. Both compounds gave negative tests for halide $\left(\mathrm{AgNO}_{3}\right.$ test) and for cystine (nitroprusside test after reduction with $\mathrm{NaCN}$ ), the only likely contaminants. Each gave a single ninhydrin spot and a single radioactive peak coincident with the ninhydrin spot on one-dimensional chromatograms run in three solvent systems.

$\mathrm{L}-\left[{ }^{35} \mathrm{~S}\right]$ Cysteine hydrochloride was prepared by the reduction of labelled L-cystine with sodium in anhydrous ammonia (du Vigneaud, Audrieth \& Loring, 1930) Ammonia was removed from the product by adding cold dilute $\mathrm{NaOH}$ and bubbling nitrogen gas through the solution. After neutralization and evaporation to dryness under reduced pressure, the hydrochloride was obtained free from $\mathrm{NaCl}$ by extraction with hot $n$-butanol.

Procedure for uptake experiments. Each radioactive compound was diluted with 
the appropriate carrier to a specific activity of about $50 \mu \mathrm{C} / \mathrm{m}$-mole and made up in the medium to a final strength of $0.156 \mathrm{~mm}$ (equivalent to $5 \mathrm{mg}$. S/1.) unless otherwise stated. At this concentration the compounds when assayed by the methods described below gave counting rates of about 6000 counts $/ \mathrm{min} . / 10 \mathrm{ml}$ medium.

Measurements of the uptake of the various sulphur compounds were carried out in $25 \mathrm{ml}$. conical flasks containing a total fluid volume of $10 \mathrm{ml}$., consisting of $5 \mathrm{ml}$. sulphate-free medium of twice the required strength (Maw, 1960), $1 \mathrm{ml}$. yeast suspension (20\% wet weight pressed yeast/vol.) and the labelled compound under study, together with other additions if any, in $4 \mathrm{ml}$. The flasks were loosely capped and shaken at 100 oscillations/min. in a thermostat at $30^{\circ}$. At suitable times pairs of flasks were removed from the bath, cooled in ice, and the contents of each centrifuged for $1 \mathrm{~min}$. in pre-cooled tubes in a Camlab bench angle centrifuge at $1200 \mathrm{~g}$. The supernatant fluids were decanted into a second pair of pre-cooled tubes and again centrifuged for $1 \mathrm{~min}$. The temperature of the contents of the tubes did not rise above $4^{\circ}$ during these stages. The final supernatant fluids, free from yeast, were removed and $5 \mathrm{ml}$. of each used for the assay of sulphur-35. When determinations were being carried out on the yeast itself, the organisms were washed by two resuspensions in ice-cold saline and centrifugation in pre-cooled tubes as before.

Extraction of yeast with trichloroacetic acid. The yeast pellet obtained by centrifugation from each flask in uptake experiments was resuspended in $10 \mathrm{ml}$. ice-cold $5 \%(\mathrm{w} / \mathrm{v})$ trichloroacetic acid (TCA) in a tube placed in ice. The suspension was stirred at intervals, and after $\mathbf{2} \mathrm{hr}$. it was centrifuged and the precipitate washed by two resuspensions in ice-cold water and centrifugation in pre-cooled tubes.

Assay of ${ }^{35} \mathrm{~S}$-sulphate in the medium. In studies on the uptake of labelled sulphate, $5 \mathrm{ml}$. of the centrifuged medium were pipetted into a tube containing $5 \mathrm{ml}$. of $\mathrm{Na}_{2} \mathrm{SO}_{4}$ solution $(0.45 \mathrm{~g}$./1.). The contents of the tube were adjusted to $\mathrm{pH} 2 \cdot 8$, $2 \mathrm{ml}$. of aqueous $1.6 \%(\mathrm{w} / \mathrm{v})$ benzidine hydrochloride added, followed $2 \mathrm{~min}$. later by $4 \mathrm{ml}$. of $95 \%(\mathrm{v} / \mathrm{v})$ ethanol in water. After standing for $10 \mathrm{~min}$. the precipitate of benzidine sulphate was collected by filtration as a $16 \mathrm{~mm}$. disk on an $18 \mathrm{~mm}$. diameter Whatman No. 1 filter paper. The paper and disk were mounted by means of Perspex cement in an aluminium planchet, and dried in a desiccator for $1 \mathrm{hr}$. The activity of the sample was determined with the aid of a thin window (1.5 mg.) $\left.\mathrm{cm}^{2}{ }^{2}\right)$ Geiger-Muller tube. The paper and benzidine sulphate disk were then removed from the planchet, and the weight of benzidine sulphate present determined by titration with $0.01 \mathrm{~N}-\mathrm{NaOH}$. The radioactivity counts were corrected for the resolving time of the equipment, for self-absorption by the disk and for background activity.

Since the incubation medium used contained only a low concentration of sulphate $(0.312 \mathrm{~mm})$, the addition of sodium sulphate during the assay was necessary to give an amount of benzidine sulphate (about $5 \mathrm{mg}$.) sufficient to ensure complete precipitation of the labelled sulphate under the conditions described and to provide a disk of uniform thickness. To obtain benzidine sulphate disks of a suitably fine and uniform texture which would spread evenly during filtration and which would not curl or fritter on drying, it was also found necessary to carry out the precipitation with a minimum of acid present, namely by using the minimum amount of $\mathrm{HCl}$ to prepare the benzidine hydrochloride. 
Assay of organic- ${ }^{35}$ S. Labelled organic-S was first converted to inorganic sulphate by a modification of Benedict's procedure (Benedict, 1909), and then precipitated as benzidine sulphate as described above. Samples $(5 \mathrm{ml}$.) of medium were evaporated to dryness in silica crucibles with the copper nitrate reagent, heated in a furnace at $460^{\circ}$ overnight, and finally transferred with $5 \mathrm{ml}$. water to tubes containing $5 \mathrm{ml}$. $\mathrm{Na}_{2} \mathrm{SO}_{4}$ solution $(0 \cdot 45 \mathrm{~g}$./1.). Samples of yeast and of the TCA-insoluble fraction of yeast were assayed in a similar manner after being transferred to crucibles with $8 \mathrm{ml}$. water together with $2.5 \mathrm{ml}$. of the sulphate-free medium. The original Benedict method gives incomplete conversion to sulphate of several sulphur compounds, including methionine, ethionine and the alkylcysteines, although cysteine, cystine and glutathione are quantitatively oxidized. It was found in the present experiments that the presence of the incubation medium in the samples prevented spattering and increased the extent of oxidation of the more intractable compounds from $70-80$ to $90-100 \%$. Whenever analyses of pure compounds were carried out, $2.5 \mathrm{ml}$. of the medium were routinely added to aid the oxidation.

\section{RESULTS}

\section{Uptake of sulphur amino acids}

Accumulation by the yeast of the various compounds under study was assessed from the percentage loss of sulphur-35 from the incubation medium. This was generally preferable to determination of the direct appearance of sulphur-35 in the yeast, since the latter requires careful washing of the yeast to free it from residual radioactivity of the medium. Comparisons were made under various conditions of the sulphur-35 which appeared in the yeast with that which disappeared from the medium. The close agreement between the two with all the labelled compounds tested justified the use of determinations made on the medium. Determinations on the yeast were, however, carried out in the trichloroacetic acid fractionation experiments described later.

Time curves were obtained for the uptake of inorganic sulphate and six sulphurcontaining amino acids at several concentrations in the medium over a $4 \mathrm{hr}$. period at $30^{\circ}$ Fig. 1 shows the results obtained at $0.312 \mathrm{~mm}$ (equivalent to $10 \mathrm{mg}$. S/l.). Four distinct patterns of accumulation were observed: (i) The uptakes of sulphate and L-methionine were similar in that they increased steadily with time, resulting ultimately in virtually complete removal of each compound from the medium. Methionine accumulation was considerably more rapid than that of sulphate, and was also greater than that of the other sulphur compounds so far tested. (ii) LCystine was not taken up by the yeast to any significant extent, and L-cysteine was taken up only at a very slow rate. (iii) DL-Ethionine accumulation took place for a period of about $1.5 \mathrm{hr}$., during which never more than $40 \%$ of the amino acid was removed from the medium. The labelled sulphur taken up was retained in the yeast during the remainder of the $4 \mathrm{hr}$. experimental period. (iv) The uptakes of $S$-methyl-L-cysteine and $S$-ethyl-L-cysteine showed characteristic features. The sulphur of these compounds was taken up rapidly for an initial period of about $1 \mathrm{hr}$. and there was then a rapid release of sulphur-35 back into the medium, amounting to $75 \%$ of the amount initially taken up in the case of $S$-ethylcysteine $(0 \cdot 312 \mathrm{~mm})$ and $48 \%$ in the case of $S$-methylcysteine $(0.312 \mathrm{~mm})$. With lower concentrations 
of $S$-ethylcysteine, more than $90 \%$ of the sulphur taken up was subsequently released.

The uptakes of all the compounds examined were unaffected by the presence of sodium fluoride $(0.5 \mathrm{~mm})$ but were markedly decreased by sodium azide $(0.5 \mathrm{~mm})$ or 2,4-dinitrophenol $\left(0.5 \mathrm{~mm}\right.$ ) and were negligible at $0^{\circ}$ (see Table 1). Yeast growth during the $4 \mathrm{hr}$. experimental period was small. No detectable growth was observed for the first $2 \mathrm{hr}$. and after $4 \mathrm{hr}$. it amounted to an increase on a dry weight basis of never more than $18-20 \%$.
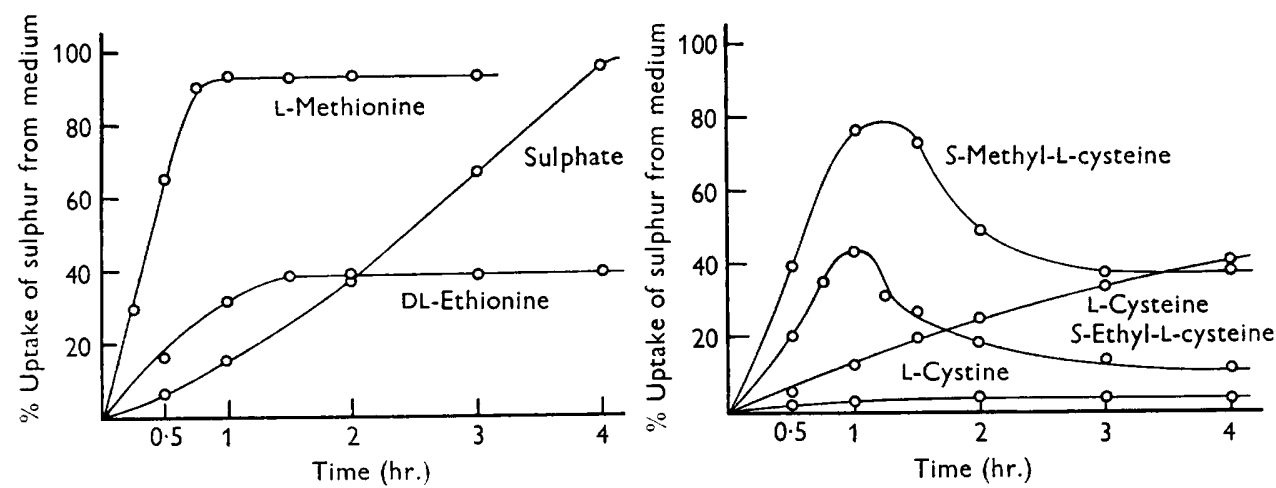

Fig. 1. Uptake of sulphur compounds by a brewer's yeast as a function of time. Compounds in medium 0.312 mm. Yeast $2 \%$ (wet weight pressed yeast/vol.). Temperature $30^{\circ}$.

Table 1. Effect of metabolic inhibitors on the uptake of sulphur amino acids by a brewer's yeast

L-[ $\left.{ }^{35} \mathrm{~S}\right]$ Cysteine $0.312 \mathrm{~mm}$, other [ $\left.{ }^{35} \mathrm{~S}\right]$ amino acids $0.156 \mathrm{~mm}$. Yeast $2 \%$ (wet wt. pressed yeast/vol.). Temperature $30^{\circ}$. Inhibitors $0.5 \mathrm{~mm}$.

\begin{tabular}{|c|c|c|c|c|}
\hline \multirow[b]{2}{*}{ Sulphur amino acid } & \multirow[b]{2}{*}{$\begin{array}{c}\text { Period of } \\
\text { uptake } \\
(\mathrm{hr} .)\end{array}$} & \multicolumn{3}{|c|}{$\%$ Decrease in uptake in the presence of } \\
\hline & & $\begin{array}{c}\text { 2,4-Dinitro- } \\
\text { phenol }\end{array}$ & $\begin{array}{l}\text { Sodium } \\
\text { azide }\end{array}$ & $\begin{array}{l}\text { Sodium } \\
\text { fluoride }\end{array}$ \\
\hline L-Methionine & $\mathbf{0} \cdot \mathbf{3 3}$ & $92 \cdot 1$ & $94 \cdot 3$ & $4 \cdot 8$ \\
\hline DL-Ethionine & $\mathbf{1}$ & $67 \cdot 4$ & $56 \cdot 3$ & $\mathbf{2} \cdot \mathbf{1}$ \\
\hline L-Cysteine & 2 & $89 \cdot 8$ & $88 \cdot 2$ & $7 \cdot 8$ \\
\hline$S$-Methyl-L-cysteine & 1 & $97 \cdot 6$ & $90 \cdot 7$ & $\mathbf{0}$ \\
\hline$S$-Ethyl-L-cysteine & $0 \cdot 75$ & $89 \cdot 7$ & $90 \cdot 8$ & - \\
\hline
\end{tabular}

Relation between amino acid uptake and concentration in the medium. Fig. 2 illustrates the effects on the accumulation of methionine, ethionine, cysteine and $S$-ethylcysteine of different concentrations of each compound in the medium, from $0 \cdot 156$ to $3 \cdot 12 \mathrm{~mm}$ (equivalent to $5-100 \mathrm{mg}$. S/l.). Data for inorganic sulphate is also given for comparison. The lengths of the uptake periods were chosen to allow for substantial but not maximum uptake. Over this concentration range the uptake of sulphate was increased only slightly $(40 \%)$ and that of methionine was about doubled. On the other hand, there was a much greater accumulation of the other amino acids, amounting to as much as a 23 -fold increase in the case of cysteine. It will be noted that above $0.312 \mathrm{~mm}$ the uptake/concentration relationships for methionine, ethionine and cysteine were roughly linear, while $S$-ethylcysteine accumulation became maximal at about $1.56 \mathrm{mv}$. 


\section{Concentration of amino acid-sulphur by yeast}

To obtain comparative data for the accumulation of the various sulphur amino acids, uptake values were recalculated as the ratio of the internal concentration of amino acid- ${ }^{35} \mathrm{~S}$ to that in the medium. Approximate values for the internal 'free space' were obtained from the wet weight of pressed yeast and dry weight determinations. Intercellular water and water occupying the cell wall space were taken
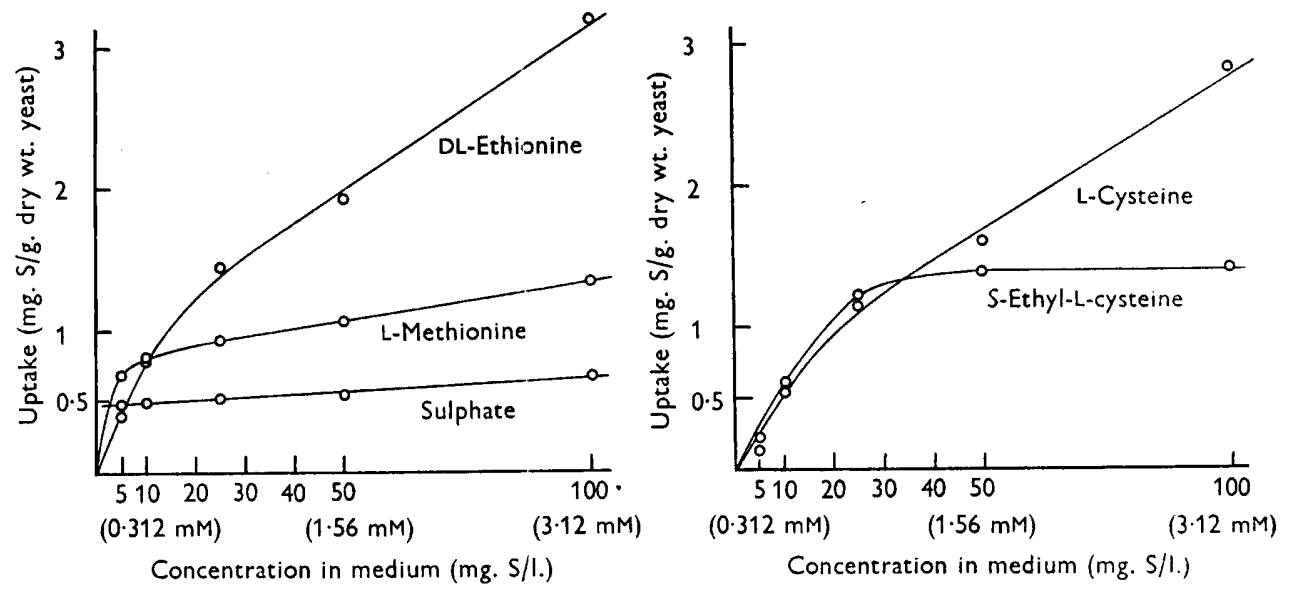

Fig. 2. Uptake of sulphur compounds by a brewer's yeast as a function of concentration. Yeast $2 \%$ (wet weight pressed yeast/vol.). Temperature $30^{\circ}$. Uptake periods: $\mathrm{Na}_{2} \mathrm{SO}_{4}$ and ethionine, $1 \mathrm{hr}$; methionine, $20 \mathrm{~min}$.; $S$-ethylcysteine, $0.75 \mathrm{hr}$; cysteine, $2 \mathrm{hr}$.

Table 2. Ability of a brewer's yeast to concentrate sulphur amino acids

$\left[{ }^{35} \mathrm{~S}\right]$ Sulphur amino acids and $\mathrm{Na}_{2}{ }^{35} \mathrm{SO}_{4} 0.312 \mathrm{~mm}$. Yeast $2 \%$ (wet wt. pressed yeast/ vol.). Temperature $30^{\circ}$. Uptake period $0.5 \mathrm{hr}$.

Ratio of internal
concentration of
35S in yeast to
concentration in
medium

$\mathbf{5 6 . 2}$
$\mathbf{1 1 . 5}$
$\mathbf{1 7 . 2}$
$\mathbf{3 0 . 5}$
$\mathbf{2 1 . 1}$
$\mathbf{4 . 9}$

as amounting to $10 \%$ of the total water in the yeast when prepared in the manner described earlier. No allowance as made for any metabolism of the amino acids which might have taken place. Table 2 shows the extent to which the yeast concentrated the sulphur of the labelled compounds after a period of $0.5 \mathrm{hr}$. when they were present in the medium at $\mathbf{0 . 3 1 2}$ mu. Methionine was clearly the most readily accumulated amino acid at the external concentration chosen, but at $3.12 \mathrm{~mm}$, owing to the greater sensitivity of uptake of the other amino acids to increase in 
concentration, the difference was not so marked and at the higher concentration methionine accumulation after $1 \mathrm{hr}$. was only twice that of ethionine.

\section{Competition studies}

The effects of several compounds on the uptake of the sulphur amino acids was examined. The compounds used were chosen for their structural or metabolic relationships with the amino acid in question, and were added to the medium at the same concentration as the sulphur amino acid and at twice, five times and ten times this concentration. The labelled amino acids were added to $0.156 \mathrm{~mm}$ except for cysteine, which on account of its low rate of uptake, was added to $0.312 \mathrm{~mm}$. The periods of uptake were chosen to provide substantial but not maximum accumulation. The results are summarized in Tables 3-7. For each of the five sulphur amino acids studied only a few compounds produced any significant effects on their accumulation, and then only when the molar ratio of added compound to sulphur amino acid was high (five to ten times greater).

\section{Table 3. Effect of various compounds on the uptake of $\mathrm{L}-\left[{ }^{35} \mathrm{~S}\right]$ methionine} by a brewer's yeast

L-[ ${ }^{35}$ S] Methionine $0.156 \mathrm{~mm}$. Yeast $2 \%$ (wet weight pressed yeast/vol.). Temperature $30^{\circ}$. Uptake period $20 \mathrm{~min}$. Effects of compounds expressed as the percentage decrease in methionine uptake compared with controls in the absence of added compounds.

Molar ratio compound/methionine

\begin{tabular}{|c|c|c|c|}
\hline 1 & 2 & $\mathbf{5}$ & 10 \\
\hline \multicolumn{4}{|c|}{$\%$ Decrease in methionine uptake } \\
\hline $1 \cdot 1$ & 1.7 & $1 \cdot 6$ & $1 \cdot 8$ \\
\hline $2 \cdot 3$ & 5.5 & $9 \cdot 0$ & $13 \cdot 2$ \\
\hline 8.5 & 14.9 & $27 \cdot 0$ & $37 \cdot 7$ \\
\hline $6 \cdot 6$ & $9 \cdot 6$ & $13 \cdot 3$ & $16 \cdot 6$ \\
\hline- & - & $15 \cdot 2$ & $21 \cdot 4$ \\
\hline $11 \cdot 8$ & $20 \cdot 9$ & $\mathbf{3 6} \cdot 3$ & 46.5 \\
\hline $16 \cdot 1$ & $26 \cdot 4$ & $40 \cdot 4$ & 45.9 \\
\hline 12.5 & 20.9 & 32.5 & $46 \cdot 0$ \\
\hline $5 \cdot 7$ & $5 \cdot 6$ & $7 \cdot 6$ & 2.5 \\
\hline - & - & $16 \cdot 9$ & $23 \cdot 3$ \\
\hline - & - & - & $8 \cdot 9$ \\
\hline - & - & - & $8 \cdot 9$ \\
\hline $7 \cdot 5$ & - & - & - \\
\hline $7 \cdot 9$ & 一 & - & - \\
\hline $14 \cdot 1$ & 一 & - & - \\
\hline
\end{tabular}

* Mixture $A$ contained the following amino acids, each $0.156 \mathrm{~mm}: \mathrm{L}-\alpha$-alanine, L-arginine.HCl, L-aspartic acid, L-citrulline, L-glutamic acid, glycine, L-proline, L-serine, L-threonine.

$\dagger$ Mixture $B$ contained the following amino acids, each $0 \cdot 156 \mathrm{~mm}$ : L-cystine.HCl, L-histidine. HCl, DL-isoleucine, L-leucine, L-lysine. HCl, L-phenylalanine, DL-tryptophan, L-tyrosine, DL-valine.

Methionine sulphoxide, methionine sulphone and ethionine were about equally effective at a ten-fold molar concentration in decreasing methionine uptake by half (Table 3); homocysteine also decreased uptake slightly, but $S$-methylcysteine and $\alpha$-aminobutyric acid were ineffective. A mixture of eighteen commonly occurring $\alpha$-amino acids, each equimolar with respect to methionine, was also without any 
marked effect. Methionine was the only effective inhibitor of ethionine accumulation, and then only when present at a five or tenfold concentration (Table 4).

In examining related thiols which might be expected to inhibit cysteine uptake, it was found that whereas homocysteine was without effect, reduced glutathione produced a distinct and reproducible increase in uptake (Table 5). In a series of six experiments increases in cysteine uptake ranging from 64.4 to $80.7 \%$ were

Table 4. Effect of various compounds on the uptake of $\mathrm{DL}-\left[{ }^{35} \mathrm{~S}\right]$ ethionine by a brewer's yeast

DL- $\left[{ }^{35} \mathrm{~S}\right]$ Ethionine 0.156 mM. Uptake period $1 \mathrm{hr}$. Other details as in Table 3.

Molar ratio compound/ethionine

\begin{tabular}{lccc}
\hline 1 & 2 & 5 & 10 \\
\multicolumn{3}{c}{ \% Decrease in ethionine uptake } \\
0 & 0 & 0 & 0 \\
$4 \cdot 7$ & $25 \cdot 5$ & $38 \cdot 2$ & $59 \cdot 6$ \\
0 & $3 \cdot 6$ & $6 \cdot 5$ & $9 \cdot 9$ \\
$2 \cdot 0$ & $4 \cdot 6$ & $11 \cdot 0$ & $17 \cdot 7$ \\
0 & 0 & 0 & $6 \cdot 4$ \\
$3 \cdot 7$ & 0 & 0 & 0
\end{tabular}

Table 5. Effect of various compounds on the uptake of $\mathrm{L}^{-\left[{ }^{35} \mathrm{~S}\right] c y s t e i n e}$ by a brewer's yeast L-[ ${ }^{35}$ S $]$ Cysteine 0.312 mM. Uptake period $2 \mathrm{hr}$. Other details as in Table 3.

$\mathrm{Na}_{2} \mathrm{SO}_{4}$

L-Methionine

$S$-Methyl-L-cysteine

$S$-Ethyl-L-cysteine

L-Cysteine. $\mathbf{H C l}$

Glutathione (reduced)
Molar ratio compound/cysteine

$\overbrace{11}^{\%} \begin{gathered}5 \\ 0\end{gathered}$

Compound added

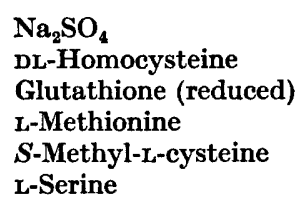

$\begin{array}{ccrr}- & - & 0 & 0 \\ -30 \cdot 0 & -41 \cdot 1 & -52 \cdot 4 & 4 \cdot 9 \\ - & - & 21 \cdot 3 & -65 \cdot 0 \\ - & - & 12 \cdot 1 & \mathbf{2 3 \cdot 3} \\ - & - & 4 \cdot 0 & 6 \cdot 0\end{array}$

Table 6. Effect of various compounds on the uptake of S-methyl-L-[ $\left.{ }^{35} \mathrm{~S}\right]$ cysteine by a brewer's yeast

$S$-Methyl-L- $\left[{ }^{35}\right.$ S $]$ cysteine $0.156 \mathrm{~mm}$. Uptake period $1 \mathrm{hr}$. Other details as in Table 3.

Molar ratio compound/methylcysteine

Compound added

\begin{tabular}{|c|c|c|c|}
\hline 1 & 2 & 5 & 10 \\
\hline \multicolumn{4}{|c|}{$\%$ Decrease in methylcysteine uptake } \\
\hline 0 & 0 & 0 & 0 \\
\hline 2.5 & $10 \cdot 9$ & 42.9 & 59.9 \\
\hline 0 & 0 & 0 & 0 \\
\hline 0 & 0 & $2 \cdot 2$ & $12 \cdot 0$ \\
\hline 0 & 0 & $3 \cdot 5$ & $10 \cdot 8$ \\
\hline
\end{tabular}

$\mathrm{Na}_{2} \mathrm{SO}_{4}$

S-Ethyl-L-cysteine

L-Cysteine. HCl

L-Methionine

L-Ethionine
0
0

$\mathbf{0}$

$10 \cdot 8$ 
produced by $3.12 \mathrm{~mm}$ reduced glutathione. $S$-Methylcysteine and $S$-ethylcysteine were effective in decreasing the uptake of each other (Table 6 and 7 ) while neither methionine nor ethionine influenced $S$-methylcysteine uptake. The effects on the uptake of $S$-ethylcysteine of several compounds tested were variable but not very large. In experiments reported earlier (Maw, 1961c) the effect of $S$-methylcysteine was less marked than that shown in Table 7, and methionine was found to be without effect.

Table 7. Effect of various compounds on the uptake of $S$-ethyl-L-[ $\left.{ }^{35} \mathrm{~S}\right]$ cysteine by a brewer's yeast

$S$-Ethyl-L-[ $\left.{ }^{35} \mathrm{~S}\right]$ cysteine 0.156 mm. Uptake period 0.75 hr. Other details as in Table 3.

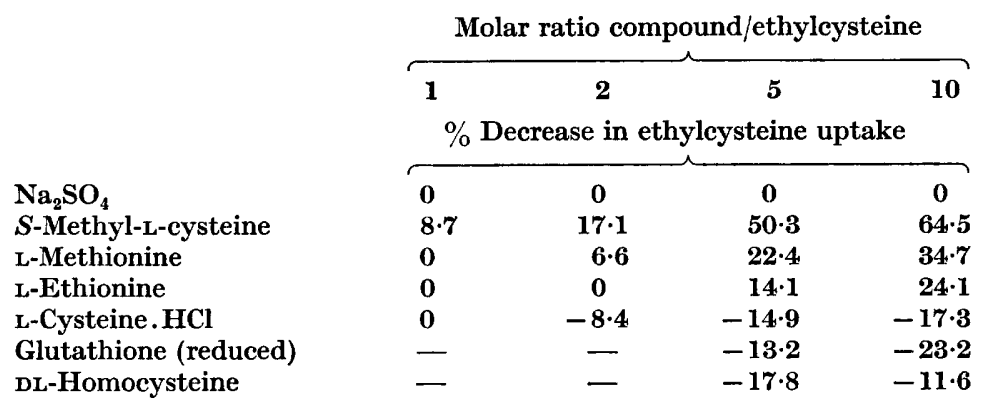

\section{Intracellular distribution of accumulated sulphur}

The distribution, between the cold trichloroacetic acid (TCA)-soluble and TCAinsoluble fractions of yeast, of the sulphur of methionine, ethionine and cysteine was determined in the presence and absence of compounds which influenced their uptake. The added compounds were present at ten times the concentration of the labelled sulphur amino acid. The data from a series of duplicated experiments are summarized in Tables 8-10. It will be seen that for all three sulphur amino acids there was some incorporation of labelled sulphur into protein, although the use of different uptake times precludes any quantitative comparisons.

Table 8. Effects of L-ethionine and DL-methionine sulphone on the partition of L-methionine-sulphur in a brewer's yeast

L-[ ${ }^{35}$ S]Methionine $0.156 \mathrm{~mm}$. L-Ethionine and DL-methionine sulphone $1.56 \mathrm{~mm}$. Yeast $2 \%$ (wet weight pressed yeast/vol.). Temperature $30^{\circ}$. Uptake period $20 \mathrm{~min}$. Figures in parentheses show the percentage decreases over the corresponding controls.

\begin{tabular}{llc}
\multicolumn{1}{c}{ Compound added } & $\begin{array}{c}\text { TCA-soluble } \\
\text { fraction }\end{array}$ & $\begin{array}{c}\text { TCA-insoluble } \\
\text { fraction }\end{array}$ \\
None & 58.5 & $11 \cdot 4$ \\
L-Ethionine & $26.1(55 \cdot 4)$ & $10 \cdot 8(5 \cdot 3)$ \\
None & $51 \cdot 3$ & $10 \cdot 4$ \\
DL-Methionine sulphone & $25 \cdot 4(50 \cdot 5)$ & $9 \cdot 0(13.5)$
\end{tabular}

The effects of ethionine and methionine sulphone on methionine uptake were markedly to decrease the entry of sulphur-35 into the TCA-soluble fraction, while incorporation into protein was not significantly affected (Table 8 ). In the inhibition 
of ethionine uptake by methionine (Table 9) quantitatively the major effect was again to decrease the entry of sulphur-35 into the TCA-soluble fraction, although the small incorporation of ethionine-sulphur into protein was also virtually abolished. The ability of reduced glutathione to enhance cysteine accumulation was likewise primarily an effect on the entry of sulphur-35 into the TCA-soluble fraction. In addition, there was an increase in appearance of sulphur-35 in the protein fraction (Table 10).

Table 9. Effect of $\mathrm{L}$-methionine on the partition of DL-ethionine-sulphur in a brewer's yeast

DL-[ $\left.{ }^{35} \mathrm{~S}\right]$ Ethionine 0.156 mM. L-Methionine 1.56 mM. Uptake period $1 \mathrm{hr}$. Other details as in Table 8.

$\begin{array}{llc}\text { Compound added } & \overbrace{\begin{array}{c}\text { TCA-soluble } \\ \text { fraction }\end{array}}^{\text {Uptake of ethionine into yeast }} & \begin{array}{c}\text { TCA-insoluble } \\ \text { fraction }\end{array} \\ \text { None } & 27 \cdot 8 & 11 \cdot 4 \\ \text { L-Methionine } & 12 \cdot 1(56 \cdot 5) & 0 \cdot 8(93 \cdot 0)\end{array}$

Table 10. Effect of reduced glutathione on the partition of cysteine-sulphur in a brewer's yeast

L-[ [as S]Cysteine. HCl, 0.312 mM. Reduced glutathione, 3.12 mM. Uptake period $2 \mathrm{hr}$. Figures in parentheses show the percentage increases over the corresponding controls. Other details as in Table 8.

Compound added
None
Reduced glutathione

$\overbrace{\begin{array}{c}\text { TCA-soluble } \\ \text { fraction }\end{array}}^{\text {Uptake of cysteine into yeast }} \begin{gathered}\text { TCA-insoluble } \\ \text { fraction }\end{gathered}$
$\begin{aligned} & 14 \cdot 9 \\ & 30 \cdot 2(104 \cdot 1)\end{aligned}$
$\begin{gathered}9 \cdot 7 \\ 13 \cdot 9(43 \cdot 3)\end{gathered}$

\section{Release of S-ethylcysteine-sulphur from yeast}

Attempts were made to examine the labelled sulphur released back into the medium following the accumulation of $S$-ethylcysteine by the yeast. Batches $\left(10 \mathrm{ml}\right.$.) of medium from flasks containing $0.312 \mathrm{~mm} S$-ethyl-L-[ $\left.{ }^{35} \mathrm{~S}\right]$ cysteine which had been shaken with yeast ( $2 \%$ wet weight pressed yeast/vol.) for $2 \mathrm{hr}$. at $30^{\circ}$ were pooled, centrifuged and loaded on to a column of Zeo Karb 225 resin ( $\mathbf{H}^{+}$form). The column was washed twice with $25 \mathrm{ml}$. water and the eluates collected separately. The column was then eluted with $\mathrm{N}-\mathrm{HCl}$ and the eluates collected in $25 \mathrm{ml}$. fractions in beakers, were evaporated to dryness and checked for radioactivity under a thin-window Geiger-Muller tube. Virtually all the radioactive material present passed straight through the column together with the glucose of the medium and appeared in the initial water washings. This contrasted with the behaviour of a $0.312 \mathrm{mM}$ solution of labelled $S$-ethylcysteine in medium added directly to the column. In this case, the radioactivity was retained on the column, was not removed in the water washings, but appeared in the first three fractions together with the bulk of the salts following elution with acid. This suggested that after being shaken with yeast, the medium contained ${ }^{35}$ S-labelled material differing from the $S$-ethylcysteine initially present. Further experiments were carried out by paper chromatographic methods. 
The centrifuged yeast-treated medium was streaked on to 3 in. wide strips of Whatman 3 MM paper and chromatographed with $n$-butanol + acetic acid + water $(4+1+5$ by vol.) as solvent. The chromatograms were then cut into 1 in. wide strips and scanned for radioactivity by using a windowless gas-flow counter. The strips showed two and sometimes three radioactive bands which were rather broad owing to the appreciable amounts of glucose and salts present in the medium. The bands were cut from the strips and eluted with water. The eluates, now largely separated from glucose and salts, were evaporated to small bulk under reduced pressure and chromatographed in the four solvents: $A, n$-butanol +acetic acid + water $(4+1+5$ by vol. $) ; B, n$-butanol + ethanol + acetic acid + water $(10+10+2+$ 5 by vol.); $C$, pyridine + methanol + water $(1+20+5$ by vol.); $D$, phenol + water $(4+1$ by vol.). When the strips were scanned for radioactivity they all revealed bands corresponding to unchanged $S$-ethyl[ $\left.{ }^{35} \mathrm{~S}\right]$ cysteine. In addition, in solvents $A$ and $B$, there was a further major band and one minor band, both with higher $\boldsymbol{R}_{F}$ values than $S$-ethylcysteine, indicating the presence of at least one new labelled compound in the medium. Chromatograms run in solvent $C$ also showed a second major band running faster than $S$-ethylcysteine and a minor band of lower $\boldsymbol{R}_{\boldsymbol{F}}$ value. In solvent $D$ no resolution occurred and only one band was obtained. Owing to shortage of material the second major labelled component of the medium has not so far been further examined.

\section{DISCUSSION}

The ability of yeasts to accumulate amino acids has been described by a number of workers. The process requires an energy source such as the fermentation of glucose (Taylor, 1949; Davies, Folkes, Gale \& Bigger, 1953; Halvorson \& Cohen, 1958; Eddy \& Indge, 1961), and aerobic conditions (Massin \& Lindenberg, 1958). It is temperature dependent and is blocked by such metabolic inhibitors as azide and 2,4-dinitrophenol (Halvorson, Fry \& Schwemmin, 1955; Halvorson \& Cohen, 1958). In several studies amino acid accumulation has been shown to be inhibited by the presence of other amino acids (Taylor, 1949; Halvorson \& Cohen, 1958; Massin \& Lindenberg, 1958). The amino acids so far studied include arginine, glutamic acid, glycine, lysine, phenylalanine, tyrosine and valine, but no information appears to be available for the sulphur-containing amino acids. In the present work, experiments with a brewer's yeast and six ${ }^{35}$ S-labelled sulphur amino acids showed marked differences in the way these compounds were taken up. L-Methionine was accumulated more rapidly than any of the other compounds, and entry into the yeast continued until this amino acid was exhausted from the medium. In contrast, there was no detectable accumulation of L-cystine, and L-cysteine entered the yeast only very slowly unless present in the medium in high concentration. This would explain why cysteine and cystine are poor sources of sulphur for the growth of this yeast.

The uptake curves for $S$-methyl-L-cysteine and its analogue, $S$-ethyl-L-cysteine, showed that these compounds were rapidly accumulated by the yeast for a short period of time, after which a large fraction of the sulphur taken up was released back into the medium. Preliminary experiments with $S$-ethylcysteine indicated the presence of at least one compound distinct from $S$-ethylcysteine which contributed 
to the released sulphur; the identity of this metabolite has not yet been established. The data on DL-ethionine illustrate a further mode of uptake. The yeast was able to remove only part of the amino acid from the medium, but the sulphur of this was retained by the organisms, in contrast to that of $S$-methylcysteine and $S$-ethylcysteine.

The accumulation of the sulphur amino acids was temperature dependent and sensitive to the presence of metabolic inhibitors. An appreciable amount of the sulphur of methionine, cysteine and ethionine which entered the yeast became associated with the protein fraction. In $2 \mathrm{hr}$. as much as $40 \%$ of the cysteinesulphur appeared in this form; with methionine, $17 \%$ of its sulphur was incorporated within 20 min.

The effects of other sulphur compounds and amino acids on the accumulation of the sulphur amino acids under study suggest that the transport mechanisms involved are fairly specific, since in every case only compounds which were closely related in structure to a given sulphur amino acid produced any change in uptake, and then only when present in considerably greater concentration. Thus ethionine, methionine sulphoxide and methionine sulphone depressed methionine uptake appreciably, in contrast to such related compounds as $S$-methylcysteine and $\alpha$ aminobutyric acid, as well as a variety of other $\alpha$-amino acids. Again, methionine was the only effective inhibitor of ethionine uptake, and $S$-methylcysteine and $S$-ethylcysteine were likewise mutually inhibitory. These very restricted competitive effects may be compared with the conclusions of other workers (Taylor, 1949; Halvorson \& Cohen, 1958; Massin \& Lindenberg, 1958) who found that the amino acid-uptake mechanisms operative in the yeasts which they used were decidedly less specific.

The ability of reduced glutathione to enhance cysteine uptake seems unlikely to be simply a protection of the cysteine-thiol group against oxidation in the medium, since it was not produced by homocysteine. Furthermore, it appears to be a specific effect since reduced glutathione had no influence on the uptake of methionine, ethionine or $S$-methylcysteine. The inhibition of methionine accumulation by ethionine and methionine sulphone and of ethionine accumulation by methionine were primarily effects on the appearance of the labelled amino acids in the nonprotein-sulphur fraction of the yeast, that is, they occurred at the stage of transport of the labelled amino acids into the cell. In addition, methionine was able to suppress almost completely the small incorporation of ethionine into protein. The increase in uptake of cysteine produced by glutathione was also primarily an effect on the transport process. This was associated with a significant increase in incorporation into protein, which might have been due to the increased availability of cysteine within the cell.

It is a pleasure to thank Mr G. A. F. Harrison for his help and advice in the radioactivity assays, Dr P. N. Campbell for a generous gift of [ ${ }^{35}$ S ]cystine, and Mr C. C. Coyne and Mr P. J. Maher for skilled technical assistance. Acknowledgement is also made to $\operatorname{Dr}$ A. K. Mills for his interest and to the Directors of Arthur Guinness Son \& Co. (Dublin) Ltd, for permission to publish this work. 


\section{REFERENCES}

Benedict, S. R. (1909). The estimation of total sulphur in urine. J. biol. Chem. 6, 363.

Davies, R., Folkes, J. P., Gale, E. F. \& Bigger, L. C. (1953). The assimilation of amino acids by micro-organisms. Biochem. J. 54, 430.

du Vigneaud, V., Audrieth, L. F. \& Loring, H. S. (1930). The reduction of cystine in liquid ammonia by metallic sodium. J. Amer. Chem. Soc. 52, 4500.

du Vigneaud, V., Loring, H. S. \& Craft, H. A. (1934). The oxidation of the sulphur of homocystine, methionine and $S$-methylcysteine in the animal body. J. biol. Chem. 105, 481.

EDDY, A. A. \& IndGe, K. J. (1961). The dependence of amino acid transport in yeast on both energy supply and extracellular potassium ions. Biochem. J. 82, 15 P.

Halvorson, H. O. \& CoHEN, G. N. (1958). Incorporation des amino-acides endogènes et exogènes dans les protéines de la levure. Ann. Inst. Pasteur, 95, 73.

Halvorson, H. O., Fry, W. \& Schwemmin, D. (1955). A study of the properties of the free amino acid pool and enzyme synthesis in yeast. J. gen. Physiol. 38, 549.

Massin, M. \& Lindenberg, A. B. (1958). Mode de fixation de la tyrosine par la cellule de levure. Aminoacides competitifs et autres facteurs d'influence. J. Physiol. (Paris), 50, 407 .

Maw, G. A. (1960). Utilization of sulphur compounds by a brewer's yeast. J. Inst. Brew. 66, 162.

MAw, G. A. $(1961 a)$. Effects of cysteine and other thiols on the growth of a brewer's yeast. J. Inst. Brew. 67, 57.

Maw, G. A. $(1961 b)$. Ability of $S$-methyl-L-cysteine to annul the inhibition of yeast growth by L-ethionine and by $S$-ethyl-t-cysteine. $J$. gen. Microbiol. 25, 441 .

Maw, G. A. $(1961 \mathrm{c})$. $S$-Methylcysteine and $S$-ethylcysteine in the sulphur metabolism of yeast. Biochem. J. 80, $28 \mathrm{P}$.

TAYLOR, E. S. (1949). The assimilation of glutamic acid by yeast. J. gen. Microbiol. 3, 211.

Williams, R. B. \& Dawson, R. M. C. (1952). The biosynthesis of L-cystine and L-methionine

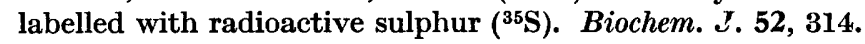

